\title{
(43-45) Three proposals to limit the principle of priority
}

\author{
Gea Zijlstra ${ }^{1}$
}

\section{(43) Add a paragraph and a note after Art. 11.2:}

"11.2bis. A name that was published in the 18th or 19th century and has not been used during the 20th century should not be reintroduced on or after 1 January 2000. Such a nomen oblitum (forgotten name) may not constitute the basionym of a name.

"Note 0 . For the purpose of Art. 11.2bis, only effectively published use of a name counts; in addition, the mentioning of a name in synonymy or its mere listing in a nomenclator or index does not constitute use of a name."

\section{(44) Add a paragraph at the end of Art. 30:}

" 30.5 . If the place in which a name was published in the 18 th or 19 th century has been neglected during the 20th century, this place of publication and its authorship should continue to be ignored after 1 January 2000: it should be treated as not effectively published."

At present, the principle of priority can be set aside only by conservation, sanctioning or (for taxonomic synonyms) rejection. The proposals on names in current use (NCU) try to set additional bounds to the unlimited application of the principle of priority. It is not sure, however, that the NCU principle will be accepted, let alone a list of names in current use. Especially for species names, in most groups of plants the acceptance of NCU lists still is far away. The present proposal may be considered as a first step toward making people aware of the need to further limit the principle of priority, an awareness that is necessary if the principle of names in current use is to be accepted.

The intention of the proposals is to put a hold to the activities of taxonomists who search obscure literature to find names of which the existence was unknown, or dig up earlier places of publications of well-known names. Two examples of the kind of exercises that would no longer be of relevance in the 21st century: Mabberley's (in Taxon 31: 65-73. 1982) list of 108 previously overlooked names of plants; and Reveal's (in Bull. Mus. Natl. Hist. Nat., B, Adansonia 13: 197-239. 1991) list with "some 310 previously unnoticed but validly published and currently available generic names ...". One of the names uncovered by Mabberley (1.c.) was Hydrostemma Wall. (Jun 1827), which had to be rejected against Barclaya Wall. (Dec 1827; see Brummitt in Taxon 36: 737. 1987).

(45) Add a second sentence to Art. 7.10, and an example:

"A type designation that was published before 1 January 1900 and has not been mentioned in a publication in the 20th century should be treated as not effectively published.

"Ex. 5bis. Margadant detected that Schimper in 1860 had indicated the type of c. 100 generic names of mosses (see Margadant \& Geissler in Taxon 44: 613. 1995). Ex-

\footnotetext{
${ }^{1}$ Herbarium, Heidelberglaan 2, NL-3584 CS Utrecht, Netherlands.
} 
cept for the concrete cases in which Schimper's type designations have been mentioned in print before 1 January 2000, they can be ignored."

This proposal aims at reducing the number of cases in which conservation of names with a conserved type is needed. Margadant's discovery has already led to several conservation proposals, e.g. Hylocomium Schimp. (Margadant \& Geissler in Taxon 44: 619. 1995). 